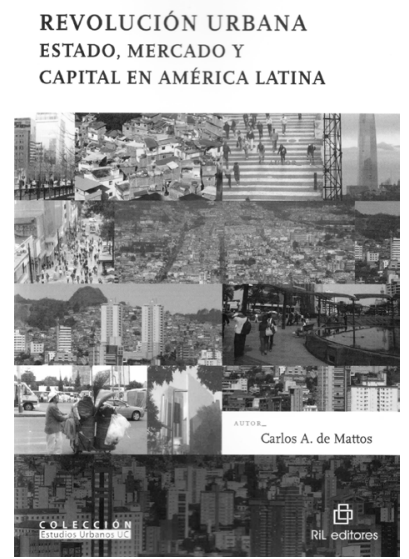

El libro que presenta Carlos de Mattos constituye una recopilación precisa de sus reflexiones sobre los problemas urbanos latinoamericanos contemporáneos, en la que se refleja un conjunto de ideas fuerza que Carlos ha desarrollado a lo largo de su vida profesional y académica.

La primera idea fuerza se refiere a la perspectiva global de Carlos sobre los temas urbano-regionales, que tiene su raíz profunda en el espíritu cepalino de pensamiento crítico. Nos referimos en particular al pensamiento desarrollado por sus fundadores, como Raúl Prebisch, Celso Furtado, Osvaldo Sunkel y Aníbal Pinto, entre otros.

Efectivamente, en todos sus trabajos se expresa una perspectiva que inserta los

\section{REVOLUCIÓN URBANA. ESTADO, MERCADO Y CAPITAL EN AMÉRICA LATINA}

\section{Carlos A. de Mattos}

SANTIAGO DE CHILE: COLECCIÓN ESTUDIOS URBANOS UC / RIL EDITORES, 2OI 5 . $320 \mathrm{P}$.

problemas urbanos y regionales en marcos analíticos más amplios, referidos a lo económico, lo social, lo político, donde son abordados desde una lógica o enfoque histórico-estructural, que es uno de los aportes principales del pensamiento de la CEPAL. Desde tal perspectiva, se postula que los problemas del desarrollo deben considerar tanto su génesis histórica como sus transformaciones y tensiones. En el caso de los problemas urbanoregionales, como los ha abordado Carlos de Mattos, ello implica que deben comprenderse considerando los marcos societales más amplios que les dan sentido, encontrando sus lógicas subyacentes y sus limitaciones y contradicciones.

Un ejemplo concreto de esta perspectiva es su temprana crítica hacia la 
planificación regional, y global, por su falta de consideración de los marcos estructurales más amplios que restringen la efectividad de dichas políticas, para generar cambios sustantivos en materia de desigualdades socioespaciales.

La segunda idea fuerza remite a su capacidad de identificar ciertos problemas fundamentales del desarrollo urbanoregional según la etapa histórica sobre la cual concentró sus reflexiones, e identificar sus implicancias. Para mencionar tres ejemplos. En los ańos ochenta puso el acento en los procesos de reestructuración productiva y social y en las nuevas modalidades de funcionamiento capitalista, basadas en la emergencia de grandes conglomerados o grupos económicos y sus implicancias territoriales para las sociedades latinoamericanas. Junto con lo anterior, elaboró una crítica profunda a las políticas de descentralización, en boga en esos años como medio efectivo de enfrentar las desigualdades socioespaciales latinoamericanas. En años recientes, la financiarización de los procesos urbanos ha estado al centro de sus preocupaciones, y en ese marco ha destacado el rol de las dinámicas financieras globales y el impacto urbano de las recientes estrategias de valorización del capital excedente surgido de los circuitos financieros mundiales.

La tercera idea fuerza es su profundo escepticismo respecto de la efectividad de las políticas urbano-regionales para enfrentar las grandes contradicciones sociales y ambientales latinoamericanas, si es que ellas no se insertan en una perspectiva de transformaciones estructurales mayores de los mecanismos o procesos generadores de desigualdad y exclusión social. De Mattos plantea, por ejemplo, que resulta absurdo pensar en enfrentar la concentración y las desigualdades socioespaciales sin que se enfrente a la vez la aguda concentración económica y social del excedente económico que impera en América Latina.

En este contexto, y como última reflexión, surge la natural pregunta sobre las alternativas, y factibilidad, del cambio social que Carlos de Mattos siempre ha considerado necesario $y$ central, pero frente al cual él sigue manteniendo una saludable perspectiva gramsciana, que puede expresarse en su famosa frase "Pesimismo de la inteligencia y optimismo de la voluntad".

Al sondear en sus trabajos buscando algunas rutas específicas de superación de las agudas desigualdades socioespaciales latinoamericanas, más de alguien puede caer en la desesperanza. Sin embargo, hay que buscar bien. En algunos de sus trabajos1, Carlos menciona, al momento de llegar a las conclusiones, algunas condiciones potenciales que podrían ayudar a detonar procesos de transformaciones mayores en materia de desigualdades urbano-regionales, y que tienen una admirable actualidad en el contexto de emergencias de múltiples y diversas acciones colectivas urbanas por todo el mundo.

Algunas citas pertinentes al respecto:

... tales proyectos no son inmutables, pues su vigencia y legitimidad está fundada en una concreta y dinámica relación de fuerzas en el proceso social y es

1 "Paradigmas, modelos y estrategias en la práctica latinoamericana de planificación regional", Documento de Trabajo ILPES, CPRD-D/88 (1988), [http://repositorio.cepal. org/handle/11362/33147]. 
lógico suponer que un proyecto que no contemple la solución de los grandes problemas sociales de un país, alberga factores que tarde o temprano terminan por conducirlo al agotamiento $y$, en definitiva, a su sustitución por otro proyecto orientado a dar efectiva respuesta a tales problemas.

b) ... las fuerzas sociales de las regiones afectadas por la persistencia y/o el agravamiento de ciertos problemas, pueden llegar a movilizarse para tratar de imponer decisiones y acciones diferentes a las que implícitamente se derivan del proyecto nacional vigente, con lo que se pueden generar contradicciones que aceleren el proceso de agotamiento de dicho proyecto.

... la participación, iniciativa y movilización regional aparece como un pre-requisito para una acción efectiva frente a los problemas regionales...

Los pocos casos que se pueden mencionar en países latinoamericanos de regiones que han logrado cierta superación de sus problemas, permiten concluir que allí la acción social regional jugó un papel fundamental para la obtención de tales resultados.

La emergencia de masivas, variadas y complejas movilizaciones sociales en múltiples ciudades del mundo, tales como las registradas en Brasil, Chile, Argentina, Ecuador, Egipto, Hong Kong, España, Grecia, etcétera, pudieran estar expresando una reacción global de la sociedad frente a las modalidades actuales de organización social. $\mathrm{Y}$ es necesario precisar que este fenómeno tiene una nítida expresión urbana: anticipa tal vez una nueva etapa donde la Sociedad adquiera un rol más prominente frente al Estado y al Mercado; un escenario que puede responder a las reflexiones de Carlos de Mattos y a las del autor que él ha estado reestudiando y rescatando en años recientes: Henri Lefebvre.

\section{Luis Riffo}

Instituto Latinoamericano y del Caribe de

Planificación Económica y Social (Ilpes)

E-MAIL: LUIS.RIFFO@CEPAL.ORG 
